\title{
Preface: Biology of the Ross Sea and surrounding areas in Antarctica
}

\author{
Diego Fontaneto $\cdot$ Stefano Schiaparelli
}

Published online: 12 October 2015

(C) Springer International Publishing Switzerland 2015

Research activities in Antarctica are rather unique for several reasons, all linked to the remoteness and hostility of the place: the history of research there is short, given that the first explorers started collecting data just over a century ago; any activity needs to be planned well in advance, months if not years; nothing can be done in a short time once there but at least weeks or months are needed to collect samples; continuous adverse weather conditions may completely change the plans; research stations follow

This volume is dedicated to the memory of Luigi Michaud (Messina, Italy, 5 October 1974-Terra Nova Bay, Antarctica, 17 January 2014).

Guest editors: Diego Fontaneto \& Stefano Schiaparelli / Biology of the Ross Sea and Surrounding Areas in Antarctica

D. Fontaneto

National Research Council, Institute of Ecosystem Study, CNR-ISE, Largo Tonolli 50, 28922 Verbania Pallanza, Italy

e-mail: diego.fontaneto@gmail.com

S. Schiaparelli

Di.S.T.A.V., University of Genova, C.so Europa 26,

16132 Genoa, Italy

S. Schiaparelli $(\bowtie)$

Museo Nazionale dell'Antartide (Sede di Genova) (MNA), Viale Benedetto XV n.5, 16132 Genoa, Italy

e-mail: stefano.schiaparelli@unige.it researchers every step of the way; internationality is the norm and everybody provides help to everybody else; an international body of rules is followed, but there is no police to control that the rules are followed, people just trust each other under those harsh conditions. Notwithstanding, or maybe exactly because of all of these oddities, Antarctic research is a flourishing field, with its own meetings, conferences and journals: unexpected surprises await at every corner, the process of biological adaptation is pushed to the extreme, and our ignorance and littleness are still incommensurably vast over there.

The area of the Ross Sea is among the best-known ones in Antarctica: the very first overwintering occurred there, at Cape Adare, the Ross Sea NW corner, where Carsten E. Borchgrevink established the base of the Southern Cross Expedition (1898-1900), setting new limits of human endurance and opening the way to several subsequent expeditions in this area, including all those that tried, and finally succeeded, to reach the South Pole in 1911 (Norwegian expedition led by Roald Amundsen) and in 1912 (British expedition led by Robert Falcon Scott).

Today, several permanent and temporary scientific stations are located on the shores of the Ross Sea, favouring the scientific connections between researchers from different countries and catalysing the increase in our biological knowledge of this remote place. Among these research stations, the oldest is that of 
"McMurdo" (USA, established in 1955-1956), which was followed by "Scott Base" (New Zealand, 1959), by "Mario Zucchelli Station" (Italy, 1985) and by the just inaugurated "Jang Bogo Station" (Korea, 2014).

The Italian research program, called PNRA (the acronym for the Italian version of National Antarctic Research Program: http://www.pnra.it) started its activity on the shores of Terra Nova Bay in the Ross Sea 30 years ago and the present volume is meant as a celebration of such continuous research activities. The volume appears exactly 15 years after the book "Ross Sea Ecology: Italiantartide Expeditions (1987-1995)" (Faranda et al., 2000), which celebrated the first 15 years of Italian research in Antarctica.

The focus on the results of the Italian research is obvious from the large number of Italian authors in the papers of the present special issue of Hydrobiologia, yet several authors from other countries worked on the Ross Sea and some of their results are included here as well. Several papers of the present volume are based on collections performed under previous international initiatives such as the Latitudinal Gradient Program (LGP, 2002-2011; http://www.lgp.aq/) or the Census of Antarctic Marine Life (CAML, 2005-2010) (Schiaparelli \& Hopcroft, 2011; Schiaparelli et al., 2013). Thanks to these large-scale projects, their logistic support and the coordinated activities they promoted, several collaborations were established and brought to results that would not have been possible through the national research programs only.

With just a little more than one century of activities, research in Antarctica is at the same time still in its infancy and well embedded in our rapidly changing world, so, all aspects of research find their deserved place and this is clearly shown in the present volume where the arrangement of the papers follows a logic that mimics what happened through time for research in other areas, but is still timely in Antarctic research. The present volume is a celebration of this scientific utopia in and around the Ross Sea, and the volume is structured in four groups of papers that (1) describe diversity in the sea and on land, demonstrating how Antarctica is, contrary to most common assumptions, biologically rich and diverse; (2) analyse the ecological correlates of such diversity, trying to infer the processes that lead to the origin of species and communities; (3) explore the extraordinary adaptations of species that thrive in the frozen world and (4) provide potential biotechnological applications from the advances in our knowledge on the Antarctic biota. The boundaries between these groups are thin and volatile, as most papers use complementary approaches crossing our classification.

Such different fields of research compete for funds in other countries, with the description of diversity often considered an old-fashioned and obsolete activity. In Antarctica, all studies have their importance and descriptive research still has a central role, given our ignorance of most of the patterns over there: the study of processes, adaptations and applications is performed in parallel with the discovery of new patterns and the establishment of simple reference baselines in newly sampled sites.

Our aim with this special issue is to thank all the researchers and funding agencies that allowed all the advances in Antarctic science and we hope that the new information contained in this special issue could be relevant to other researchers operating in the area under the umbrella of the new SCAR research programs (http://www.scar.org/srp) "State of the Antarctic Ecosystem" (AntEco) and Antarctic Thresholds-Ecosystem Resilience and Adaptation (AnT-ERA), which aim at studying, respectively: (i) the past and present patterns of biodiversity across all Antarctic environments in the Southern Ocean regions and (ii) the biological processes acting at ecological time scales, especially related to environmental and climate change. We also hope to attract more scientists to the beauty and the potentials of working with Antarctic biology.

Acknowledgements We wish to thank all the contributors of this special issue, who enthusiastically answered our call for papers. We thank also all the Antarctic scientists who are not present in this volume, but on whose shoulders the results presented in this volume were built. A special acknowledgement is for all reviewers that dedicated time to the revision of the papers in this special issue and helped in improving the initial drafts submitted with their advice and suggestions. Of course, research in Antarctica will not be possible without large funds from the National and International funding agencies: we thank them all! More specifically, we thank the Italian PNRA (http:// www.pnra.it) for 30 years of continuous funding and for funding the activities of the guest editors in Antarctica, all the personnel of Mario Zucchelli Station (http://www.polarnet.cnr.it/ content/view/161/58/lang,en/) in Terra Nova Bay for their continuous logistic support, and the Italian National Antarctic Museum (Section of Genoa) (http://www.mna.it) for support during the process of the creation of this volume. 


\section{References}

Faranda, F. M., L. Gulielmo \& A. Ianora (eds), 2000. Ross Sea Ecology: Italiantartide Expeditions (1987-1995). Springer, Berlin: 1-604.

Schiaparelli, S. \& R. R. Hopcroft, 2011. The Census of Antarctic Marine Life: diversity and change in Southern Ocean ecosystems. Deep-Sea Research. Part 2. Topical Studies In Oceanography 58: 1-4.

Schiaparelli, S., B. Danis, V. Wadley \& D. M. Stoddart, 2013. The Census of Antarctic Marine Life: The First Available Baseline for Antarctic Marine Biodiversity. In Verde, C. \& G. di Prisco (eds), Adaptation and Evolution in Marine Environments, Vol. 2., From Pole to Pole Springer, Berlin: 3-19. 